\title{
Incidence of Urinary Problems Post Successful Fistula Repair
}

\author{
Nasira Tasnim, Kauser Bangash, Oreekha Amin, Afshan Batool, Nosheela Javed \\ Department of Maternal and Child Health, Pakistan Institute of Medical Sciences, Islamabad, Pakistan
}

DOI : http://dx.doi.org/10.3126/njog.v13i2.21700

\begin{abstract}
Aims: The aim was to determine the incidence and association of urinary problems post successful fistula repair

Methods: The retrospective analysis was conducted at Maternal Child Health Pakistan Institute of Medical Sciences, Islamabad, and comprised data related to patients having undergone vesicovaginal fistula repair from January 2008 to June 2018. Various modalities were used to determine the underlying cause of these symptoms including patient's history, examination, ultrasound, urine examination and urodynamic studies. Statistical analysis of the record was done using SPSS 21 software.
\end{abstract}

Results: Among total 318 successful fistulas repair patients, $78(24.5 \%)$ had urinary problems post operatively. Out of these $78,56.4 \%$ had stress incontinence, $41 \%$ infection and $2.6 \%$ urge incontinence. $13.6 \%$ of the stress incontinence was due to sphincter weakness Urge incontinence was found to be due to detrusor instability. These post-operative urinary complaints were significantly associated with the repair of vesicovaginal (31.3\%), urethral (23.1\%) and vesicouterine (15.7\%) fistula compared to those involving ureter(p 0.04$)$. No significant association was found between the incidence of post-operative urinary complaints and previous history of surgical repair, parity, fistula size and duration of fistula.

Conclusions: Urinary incontinence after fistula repair requires careful evaluation as the successful repair of a urogenital fistula can correct the fistula defect, but it might not make the patient dry. Moreover, performing further continence surgery may exacerbate the condition in some cases.

Key words: fistula, infection, incontinence, urogenital.

\section{INTRODUCTION}

Urogenital fistula is an abnormal communication between the urinary tract and the genital region. Its prevalence is higher in developing countries than in the developed countries (0.3-2\%). ${ }^{1}$ As reported, the prevalence of vesicovaginal fistula in the reproductive age group is 1.60 per 1000 women in South Asia. ${ }^{2}$ The reported success rate of urogenital fistula repair varies from $87-93 \% .^{3,4}$ However, urogenital fistula repair poses a considerable challenge in terms of a successful surgical outcome. Despite the successful fistula repair, many patients may continue to complain about the persistence of symptoms in terms of frequency, urgency, urge incontinence and stress incontinence. ${ }^{5,6}$ A low bladder capacity, simultaneous involvement of the bladder support at the time of insult are contributory factors. The reported overall incidence of these complaints is 18$33 \%$. $^{7}$ A successful surgery is also challenging due to scarring and poor health of the tissue especially in cases of previous multiple repair attempts. ${ }^{8}$ Similarly, a study reported significant association of residual

\section{CORRESPONDENCE}

Dr Oreekha Amin

Department of Maternal and Child Health,

Pakistan Institute of Medical Sciences, Islamabad, Pakistan

Email: oreekha@gmail.com urinary problems after successful fistula repair with the level of urethral involvement, and vaginal scarring. ${ }^{9}$ Moreover, urinary incontinence after fistula repair requires careful evaluation as executing further surgical attempts may worsen the condition. In our study, a review of successfully repaired fistula was done to determine the incidence of post successful repair urinary problems and to identify factors for these urinary complaints.

\section{METHODS}

The retrospective study was conducted at Maternal Child Health Pakistan Institute of Medical Sciences, Islamabad, on women who had undergone urogenital fistula repair from January 2008 to June 2018. Ethical review board approval was obtained. All patients who had their fistula repaired at the hospital were included in the study. Data was collected regarding patient's age, parity, type of fistula, duration and size of fistula. All patients underwent examination under anesthesia, intravenous urography and cystoscopy (if required) in order to identify the characteristics of fistula. Based on accessibility of fistula from vagina, decision was made about the route of surgery (vaginal/ abdominal). None of our patients had previous pelvic irradiation. Post-operatively, all the patients remained catheterised for a period of 21 days. Assessment for 
successful fistula closure and stress incontinence after surgery was done using a dye test before discharge. Data was analysed using SPSS 21 . Chi-square test was used to determine the association of predictors of outcome of urogenital fistula repair ( $\mathrm{p} \leq 0.05$ was considered as significant).

\section{RESULTS}

The mean age of the patients was $34.16 \pm 10.26$ years (range:15-75). Out of 318 successful fistula repair patients, $78(24.4 \%)$ had post-operative urinary complaints. Among 78, $41 \%$ patients' complained of urinary infection, $56.4 \%$ had stress incontinence and $2.6 \%$ had urge incontinence (Figure 1).

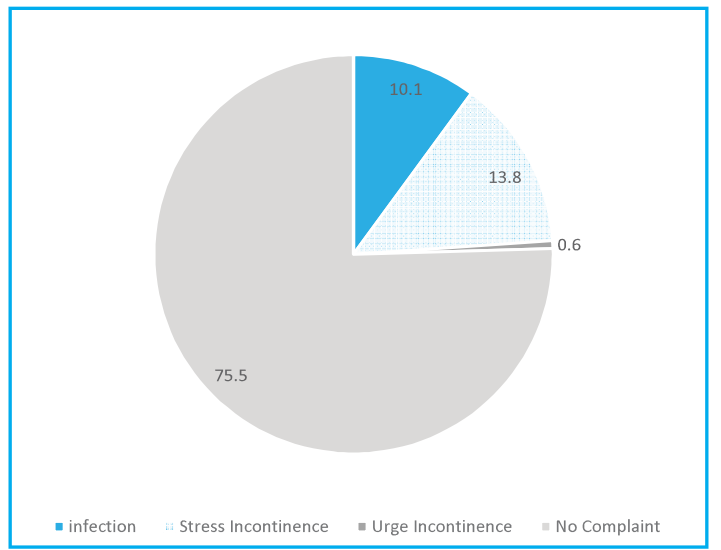

Figure 1. Percentages of patients with post-operative urinary complaints.

Various modalities were used to determine the underlying cause of these symptoms including detailed history, urogenital examination, ultrasound for post void residual urine volume, urine examination and urodynamic studies. Urodynamic studies of the 78 patients having post-operative urinary complaints revealed sphincter weakness in $7.7 \%$ and detrusor instability in $2.4 \%$ of the cases. Moreover, urinary complaints were significantly associated with the type of fistula repair done. Out of these 78 patients, 60 (77\%) had vesicovaginal, 4 (5\%) vesicouterine, 13 (17\%) urethral, 1 (1\%) ureterouterine type of fistula, as shown in Table 1 (p0.045).

Table 1: Percentages of urinary complaints among patients with type of fistula.

\begin{tabular}{|l|l|l|l|l|l|}
\hline & Vesico-vaginal & Vesicouterine & Urethral & Ureteric & Ureterouterine \\
\hline $\begin{array}{l}\text { Urinary } \\
\text { Complaints }\end{array}$ & $66(77 \%)$ & $4(5 \%)$ & $13(17 \%)$ & 0 & $1(1 \%)$ \\
\hline $\begin{array}{l}\text { Stress } \\
\text { Incontinence }\end{array}$ & $35(60 \%)$ & - & $9(69 \%)$ & & \\
\hline & - & - & & & \\
\hline $\begin{array}{l}\text { Urge } \\
\text { Incontinence }\end{array}$ & $1(2 \%)$ & - & $1(8 \%)$ & - & - \\
\hline Infection & $24(40 \%)$ & $4(100 \%)$ & $3(23 \%)$ & - & $1(100 \%)$ \\
\hline
\end{tabular}

There is no association of post-operative urinary complaints with parity $(0.15)$, fistula size $(\mathrm{p}=0.16)$, duration of fistula $(\mathrm{p}=0.9)$ and previous repair attempt $(\mathrm{p}=0.43)$, as shown in Table 2 .

Table 2: Association of post successful urogenital fistula repair urinary complaints with various factors using chisquare test.

\begin{tabular}{|l|l|l|l|l|l|}
\hline & Infection & $\begin{array}{l}\text { Stress } \\
\text { Incontinence }\end{array}$ & $\begin{array}{l}\text { Urge } \\
\text { Incontinence }\end{array}$ & $\begin{array}{l}\text { No urinary } \\
\text { complaint }\end{array}$ & P value \\
\hline Parity (n) & & & & & $\mathbf{0 . 1 5}$ \\
\hline $0(142)$ & $8 \%$ & $4 \%$ & $4 \%$ & $84 \%$ & \\
$<4(192)$ & $10 \%$ & $13 \%$ & $0 \%$ & $77 \%$ & \\
$>4(30)$ & $10 \%$ & $14 \%$ & $1 \%$ & $75 \%$ & \\
\hline Fistula Size (n) & & & $1 \%$ & & $\mathbf{0 . 1 6}$ \\
\hline $1.5(148)$ & $25 \%$ & $0 \%$ & $5 \%$ & $70 \%$ & \\
$1.5-3(161)$ & $23.8 \%$ & $0 \%$ & $0 \%$ & $76.2 \%$ & $85.7 \%$ \\
$>3(55)$ & $0 \%$ & $14.3 \%$ & $0 \%$ & & \\
\hline
\end{tabular}




\begin{tabular}{|l|l|l|l|l|l|}
\hline $\begin{array}{l}\text { Duration of } \\
\text { fistula (n) }\end{array}$ & & & & & 0.9 \\
\hline $3-6$ months (51) & $17.8 \%$ & $3.6 \%$ & $3.6 \%$ & $75 \%$ & $66.7 \%$ \\
$6-12$ months & $33.3 \%$ & $0 \%$ & $0 \%$ & $81.8 \%$ & \\
$(127)$ & $18.2 \%$ & $0 \%$ & $0 \%$ & $50 \%$ & \\
$2-5$ yr (157) & $50 \%$ & $0 \%$ & & & \\
$6-10$ yr (29) & & & & 0.43 \\
\hline $\begin{array}{l}\text { Previous repair } \\
\text { attemp }\end{array}$ & & & $0 \%$ & $81 \%$ & \\
\hline $0(122)$ & $7.1 \%$ & $11.9 \%$ & $0.8 \%$ & $74.6 \%$ & \\
$1(141)$ & $9.5 \%$ & 15.1 & $0 \%$ & $75 \%$ & \\
$\geq 2(101)$ & $20.8 \%$ & $4.2 \%$ & & & \\
\hline
\end{tabular}

\section{DISCUSSION}

Urogenital fistulas are perhaps the most distressing complications among obstetric patients and those undergoing gynecological pelvic surgery. Therefore, having the fistula successfully repaired is paramount because success rate decreases with the increasing number of surgical repair attempts. ${ }^{10,11}$ Further, despite the defect being successfully closed, this does not necessarily be equivalent to a complete cure.

The post-operative urinary complications after successful surgical repair of fistula are not uncommon (including urinary stress incontinence, overactive bladder, mixed urinary incontinence and voiding dysfunction). Causes of ongoing urinary incontinence after fistula closure include urodynamic stress incontinence, detrusor overactivity and voiding dysfunction. ${ }^{9}$ The post-operative urinary incontinence in a successfully repaired urogenital fistula patients is a complicated issue. Often, this is due to scarred tissue that is left behind with no or impaired physiological function. Further, the bladder tissue itself may be damaged or weakened during the pelvic surgery or labour. The bladder wall may become scarred due to fibrosis and thus affecting its physiological function as a reservoir and being a compliant organ. Therefore, predicting the risk factors and evaluation these patients before hand is important in order to be able to avoid the development or persistence of postoperative urinary complaints.

Previously, a study reported post-operative residual incontinence rate of $33 \%$ despite successful closure of the vesico-vaginal fistula. ${ }^{12}$ Another study reported that ongoing urinary incontinence occurred in $23.9 \%$ of women after successful fistula closure. ${ }^{8}$ Similarly, in our study out of 318 patients of successful fistula repair, $24.4 \%$ (78) had urinary complaints. Further, a UK based study reported $50 \%$ of patients had detrusor instability and $11 \%$ had stress incontinence after successful fistula repair. ${ }^{13}$ However, an Ethiopia based study reported 30 women with persisting urinary incontinence. Out of these, $57 \%$ had stress incontinence and $7 \%$ detrusor instability. ${ }^{14}$ In our study, we observed stress incontinence in $56.4 \%$, urinary infection $\mathrm{in}^{41 \%}$ and detrusor instability in $2.6 \%$ of 78 patients who had post-operative urinary complaints. This difference might be due to different aetiology or type of urogenital fistula. As in developed countries most common cause of fistula is iatrogenic during surgical handling. Prolonged and/or obstructed labour is the most common cause of genital tract fistula in under developed countries, in particular, Sub-Saharan Africa and parts of Asia where emergency obstetric services are unavailable or suboptimal to afford timely delivery of the baby.

Although, some of the previous studies reported the increased incidence of patients complaining of postoperative urinary complaints with the history of previous repair attempt.. ${ }^{8,9}$ However, in our study no association of post-operative urinary complaints and history of previous fistula repair attempts was found. Similarly, no association was observed for duration of fistula, size of fistula and parity of patients.

In our study, there was certain limitation regarding performing urodynamic studies in all patients due to non-affordability of patients. Therefore, there could have been challenges in patient assessment. Yet, our study, with a large number of cases, shows an effort to analyse the factors which provide the best chances of successful closure of the fistula. 


\section{REFERENCES}

1. Eilber KS, Kavaler E, Rodriguiz LV, Rosenblum N, Raz S Ten-year experience with transvaginal vesicovaginal fistula repair using tissue interposition. J Urol. 2003;169:1033-6.

2. Adler AJ, Ronsmans C, Calvert C, Filippi V. Estimating the prevalence of obstetric fistula: a systematic review and meta analysis. BMC Pregnancy Childbirth. 2013;13:246

3. Muleta M. Obstetric fistula: a retrospective study of 1210 cases at the Addis Ababa Fistula Hospital. J ObstetGynaecol. $1997 ; 17(1): 68-70$

4. Gessessew A, Mesfin M. Genitourinary and rectovaginal fistulae in Adigaft Zonal Hospital, Tigray, northern Ethiopia. Ethiopia Med J. 2003;41:123-30

5. Browning A. Prevention of residual urinary incontinence following successful repair of obstetric vesicovaginal fistula using a fibromascular sling. BJOG. 2004;111:357-61.

6. Holme A, Breen M, MacArthur C. Obstetric fistula: a study of women managed at the Monze Mission Hospital, Zambia. BJOG. 2007; 114:1010-7.

7. Browning A. A new method for preventing residual urinary incontinence after successful closure of vesico-vaginal fistula BJOG. 2004;111:357-61
8. Goh JT, Browning A, Berhan B, Chang A. Predicting the risk of failure of closure of obstetric fistula and residual urinary incontinence using a classification system.Int Urogynecol J Pelvic Floor Dysfunct. 2008 Dec;19(12):1659-62

9. Kayondo M, Wasswa S, Kabakyenga J, Mukiibi N, Senkungu J, Stenson A, Mukasa P. Predictors and outcome of surgical repair of obstetric fistula at a regional referral hospital, Mbarara, western Uganda. BMC urology. 2011 Dec;11(1):23.

10. Wall LL, Karshima JA, Kirschner C, Arrowsmith SD. The obstetric vesicovaginal fistula. Characteristics of 899 patients from Jos, Nigeria. Am J Obstet Gynecol. 2004;190:1011-6.

11. Javed A. Doctor! Will I be dry? Factors determining recurrence after vesicovaginal fistula repair. JPMA. 2015;65(9):954.

12. Kelly J, Kwast B. Epidemiologic study of vesicovaginal fistulas in Ethiopia. Int J Urogynaecol. 1993;4:278-81.

13. Hilton $\mathrm{P}$. Urodynamic findings in patients with urogenital fistulae. Br J Urol. 1998;81:539-42.

14. Murray C, Goh JT, Fynes M, Carey MP. Urinary and faecal incontinence following delayed primary repair of obstetric genital fistula. BJOG. 2002;109:828-32. 